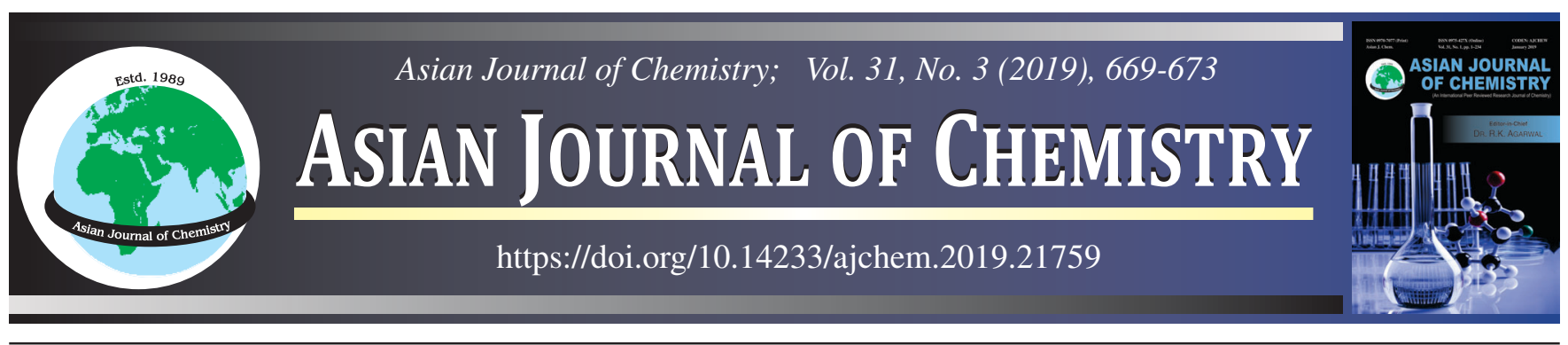

\title{
in silico Approach Towards Antiinflammation and Anticancer Studies on Phytoconstituents Derived from Cissus quadrangularis
}

\author{
Vidya Edathil and Gopal Selvi
}

Department of Chemistry, P.S.G.R. Krishnammal College for Women, Coimbatore-641004, India

*Corresponding author: E-mail: selvi_gv@ rediffmail.com

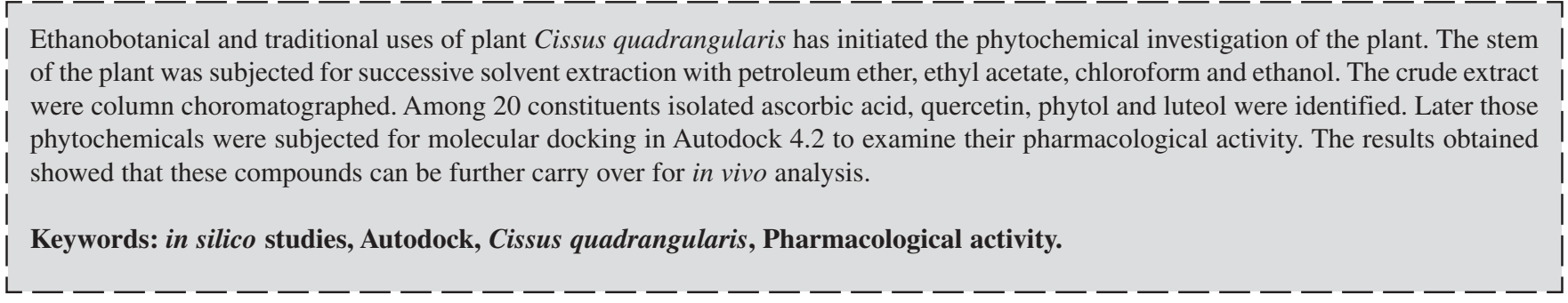

\section{INTRODUCTION}

Cissus quadrangularis (Linn) is a common climber and has been used by common man in India for fracture healing and well known as "Hadjod", which belongs to family Vitaceae. It is distributed throughout India particularly in tropical regions. Plant is propagated using cuttings and it flowers in the month of June-December. The plant is known as Perandi in Tamil, Vajravalli in Sanskrit, Hadjod in Hindi, Nalleru in Telugu and Veldgrap, edible stemmed vine in English. It is commonly known as veldt grape or devils backbone [1,2]. It is used in indigenous system of medicine like Ayurveda, Sidha, Unani and Homeopathy. The bone healing property of cissus make it as good drug for osteoporosis. A number of studies revealed the effect against gastric toxicity and the gastroprotective effect of Cissus quadrangularis [1]. The literature reports of Cissus quadrangularis predicts that it acts as potent antioxidant, anticancer, analgesic, anti-inflammatory, antipyretic and anti-diabetic agent [3-11] and used also as an apetite increaser.

The plant which was collected from Pollachi area Tamil Nadu was identified by BSI, Agriculture University campus, Tamil Nadu, India. The stem of the plant was shade dried, powdered and extracted with petroleum ether, ethyl acetate, chloroform and ethanol successively. Around 20 costituents were isolated by column chromatography from the residual extracts of petroleum ether, chloroform, ethyl acetate and ethanol and identified by spectral analysis.

As a new dimension in silico studies were carried out to recognize yet another pharmaceutical versatility of the isolated compounds. In this context, we have chosen ascorbic acid, quercetin, phytol and luteolin for docking against BRCA1 and COX2, which give response to breast cancer and inflammation [12-14], respectively. The drug-likeness of selected drugs and mode of binding with selected enzymes were studied. The results obtained were found to be good. For docking studies, we have chosen latest Autodock 4.2 and the enzymes were selected from RSCB protein data bank. Structures of the compounds were generated by using chem Sketch. The drug's potent interaction forms number of hydrogen bonds with enzymes having more negative binding energies.

\section{EXPERIMENTAL}

Quercetin, phytol, luteolin, ascorbic acid are the molecules selected for docking studies. The physio-chemical properties and the structures of these compounds were collected from the PubChem database (www.ncbi.nlm.nih.gov/pubchem).

COX-1 and COX-2 are two isoforms of cyclooxygenase enzyme, which is crucial for the production of prostaglandins

This is an open access journal, and articles are distributed under the terms of the Creative Commons Attribution-NonCommercial-ShareAlike 4.0 (CC BY-NC-SA 4.0) International License which allows readers to freely read, download, copy, distribute, print, search, or link to the full texts of its articles and to use them for any other lawful non-commercial purpose as long as the original source is duly acknowledged. 
[12-15]. COX-2 is involved in the inflammatory pain found in central nervous system and in inflammatory cells. Even though NSAIDs have the ability to inhibit COX-2 enzymes, various side effects such as intestinal and renal functional suppression were also observed. The Protein Data Bank (PDB) provides the information about the 3D structure of protein, which is given in Fig. 1. The PDB ID is 6cox which is a complex of COX-2 enzyme with selective inhibitor SC-558 [16,17].

Breast cancer, the most threatening cancer among women. A million women are affected with breast cancer annually. Breast cancer Type 1 susceptibility protein early onset (BRCA1) is a human estrogen sensitive tumor suppressor gene and is an established DNA repair gene. The 3D structure of BRCA1 enzyme protein structure was taken from PDB database (PDB:1T2U) $[18,19]$. The three-dimensional crystal structure of enzyme is shown in Fig. 1.

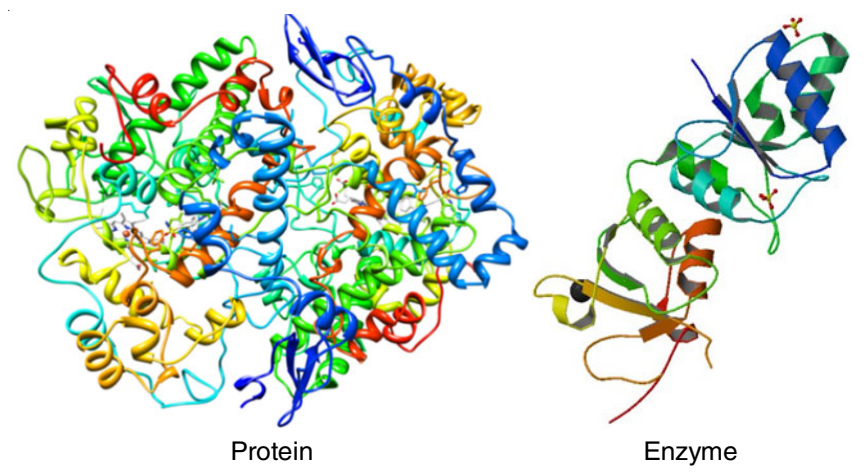

Fig. 1. 3D structures of protein and enzyme

Active site identification: Active site of BRCA1 and COX-2 were identified using CASTp server. A new program, CASTp, can be used for locating protein pockets and cavities. It is based on precise computational geometry methods.

\section{Softwares}

Python 2.7: This language was downloaded from www. python.com, Cygwin (a Data storage) c:Iprogram and Python 2.5 were simultaneously downloaded from www.cygwin.com, Molecular graphics laboratory (MGL) tools and AutoDock 4.2, Discovery studio visualizer 2.5.5 were also downloaded. ChemSketch, which was used to draw the structure was downloaded from www.acdlabs.com.

Docking study was performed for the compounds obtained after separation through column chromatography followed by spectral analysis. The structures of the ligands were drawn using ChemSketch in order to obtain the MOL format. The MOL files were converted to PDB format using Open Babel tool. The receptors taken for docking were chosen from RSCB protein Data Bank database. Selection of receptor depends on their role in bacterial life cycle. Initially, heteroatoms were removed from the receptor. Then hydrogen bonds and charges were added to the receptor using Autodock 4.2. Docking was carried out by increasing the grid box size so that the whole protein was accommodated. PDBQT files of target and ligand, gpf and dpf files were retrieved using Autodock 4.2. Molecular docking was done using software known as Cygwin. The final docked complex was thus formed using cygwin. Results with 10 different conformations were obtained. The conformation with a minimum binding energy was selected. The docked complex was analyzed with Discovery studio visualizer. The ligand binding patterns were well visualized by this tool [20].

\section{RESULTS AND DISCUSSION}

Lipinski rule of five analysis: The drug-likeness of the compound must be evaluated at the initial stage as this reduces the chances of selecting the false positive results. It gives an idea about different physico-chemical properties such as $\log \mathrm{P}$, $\mathrm{H}$-bond acceptor, $\mathrm{H}$-bond donor, molecular weight and molar refractivity were calculated to evaluate a molecule to act as drug. The value of $\log \mathrm{P}$ should be $\leq 5$; this is the distribution coefficient important for finding the solubility of the drug that is lipophilicity. As most of the drugs are small molecules, molecular weight of the each one should not exceed 500 Dalton. The physical properties of ligand molecules and their drug likeness score is tabulated in Table- 1 .

In the case of molecules mentioned above phytol does not obey the Lipinski rule of five in which Log P values exceeds the limit. And hence it cannot be considered as an active drug for further docking studies.

Docking: Docking study explained that the ligands bind to the receptor with a good binding energy. The hydrogen bonds formed refers to the strength of binding between the ligand and the receptor. Table- 2 shows the binding energy of ligand with the receptor in $\mathrm{kcal} / \mathrm{mol}$, number of hydrogen bonds formed between ligand and amino acid. Compounds exhibiting higher negative binding energy contribute to the maximum activity . The docking of four among the isolated compounds ascorbic acid, luteolin, quercetin and phytol is given in Table-2.

\begin{tabular}{lc}
\multicolumn{2}{c}{ TABLE-2 } \\
\multicolumn{1}{c}{ BINDING ENERGY MEASUREMENTS } \\
\hline \multicolumn{1}{c}{ Compound } & Binding energy $(\mathrm{kJ} / \mathrm{mol})$ \\
\hline Ascorbic acid $v$ s. COX2 & -5.54 \\
Luteolin $v s$. COX-2 & -7.94 \\
Quercetin $v$ s. COX-2 & -5.37 \\
Quercetin $v$ s. BRCA-1 & -5.89 \\
Ascorbic acid $v s$. BRCA-1 & -3.63 \\
Luteolin $v s$. BRCA-1 & -5.59 \\
\hline
\end{tabular}

It is evident from Table-2 that ascorbic acid has a lower $\log \mathrm{P}$ value than others which indicates that the former has higher hydrophobic activity than the latter. The interaction energy

TABLE-1

PHYSICAL PARAMETERS OF DRUGS

\begin{tabular}{cccccccc}
\hline Ligand/Drug & m.w. & $\begin{array}{c}\text { HBA } \\
<\text { than } 10\end{array}$ & $\begin{array}{c}\text { HBD } \\
<\text { than } 5\end{array}$ & $\begin{array}{c}\log \mathrm{P}< \\
\text { than } 5\end{array}$ & $\begin{array}{c}\log \mathrm{S} \\
(\mathrm{mol} / \mathrm{L})\end{array}$ & $\begin{array}{c}\text { Druglikeness } \\
\text { score }\end{array}$ \\
\hline Vit C & 176.03 & 6 & 4 & -2.40 & 0.44 & $85.73 \mathrm{~A}^{2}$ & 0.84 \\
Phytol & 296.31 & 1 & 1 & 8.28 & -5.27 & $17.17 \mathrm{~A}^{2}$ & -0.87 \\
Quercetin & 302.04 & 7 & 5 & 2.11 & -3.87 & $102.61 \mathrm{~A}^{2}$ & 0.93 \\
Luteolin & 286.05 & 6 & 4 & 2.68 & -4.07 & $89.05 \mathrm{~A}^{2}$ & 0.86 \\
\hline
\end{tabular}


for the ligand-receptor complex under study determines best ligand for docking studies. The above results uphold luteolin is a more promising drug against inflammation because of its lower interaction energy $(-7.94 \mathrm{kcal})$. In the case of anti-cancerous activity quercetin is more active as it shows less binding energy $(-5.89 \mathrm{~kJ} / \mathrm{mol})$.
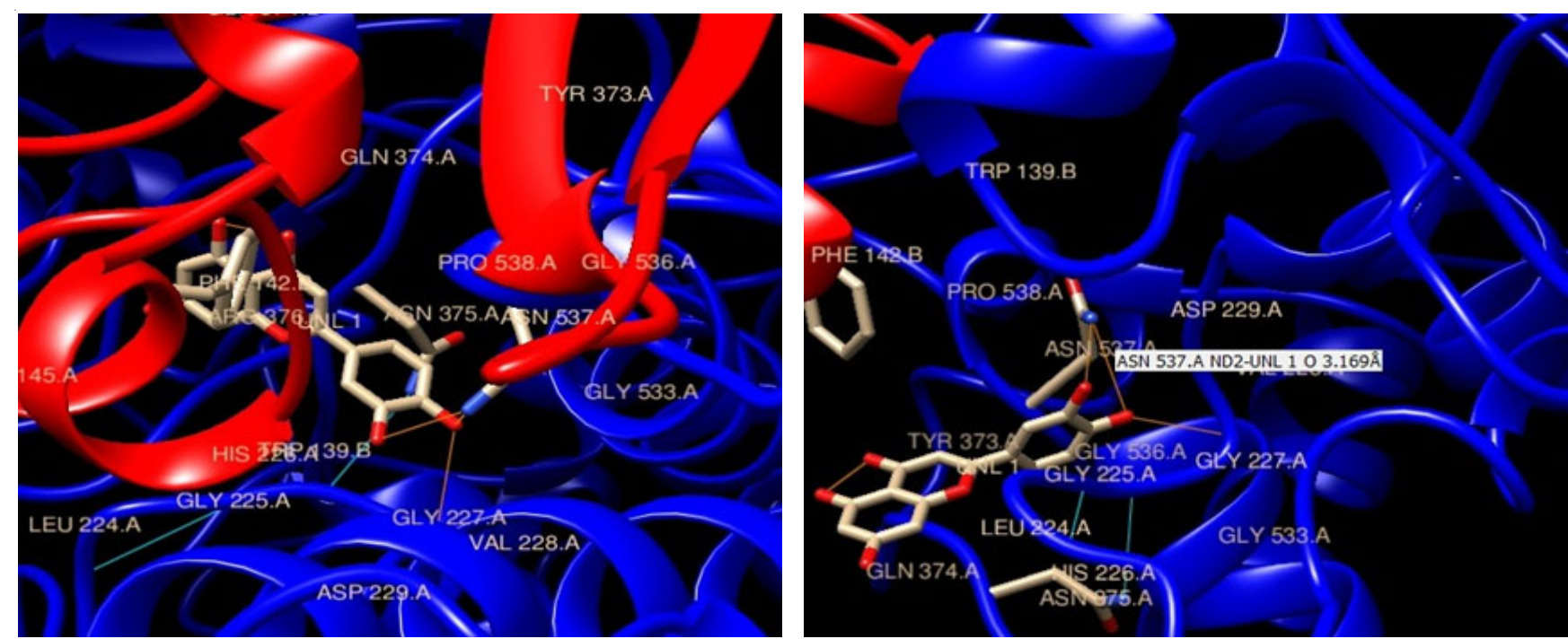

COX2-Luteolin
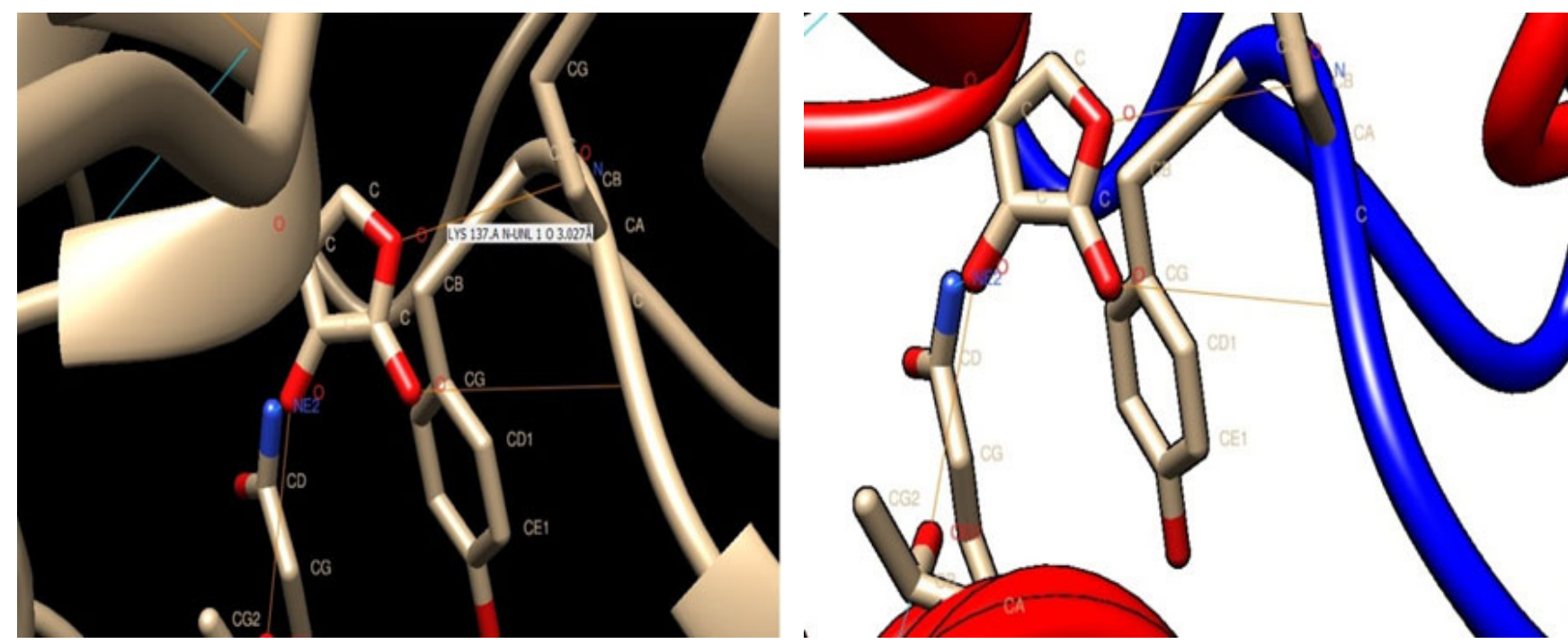

COX2-Ascorbic acid
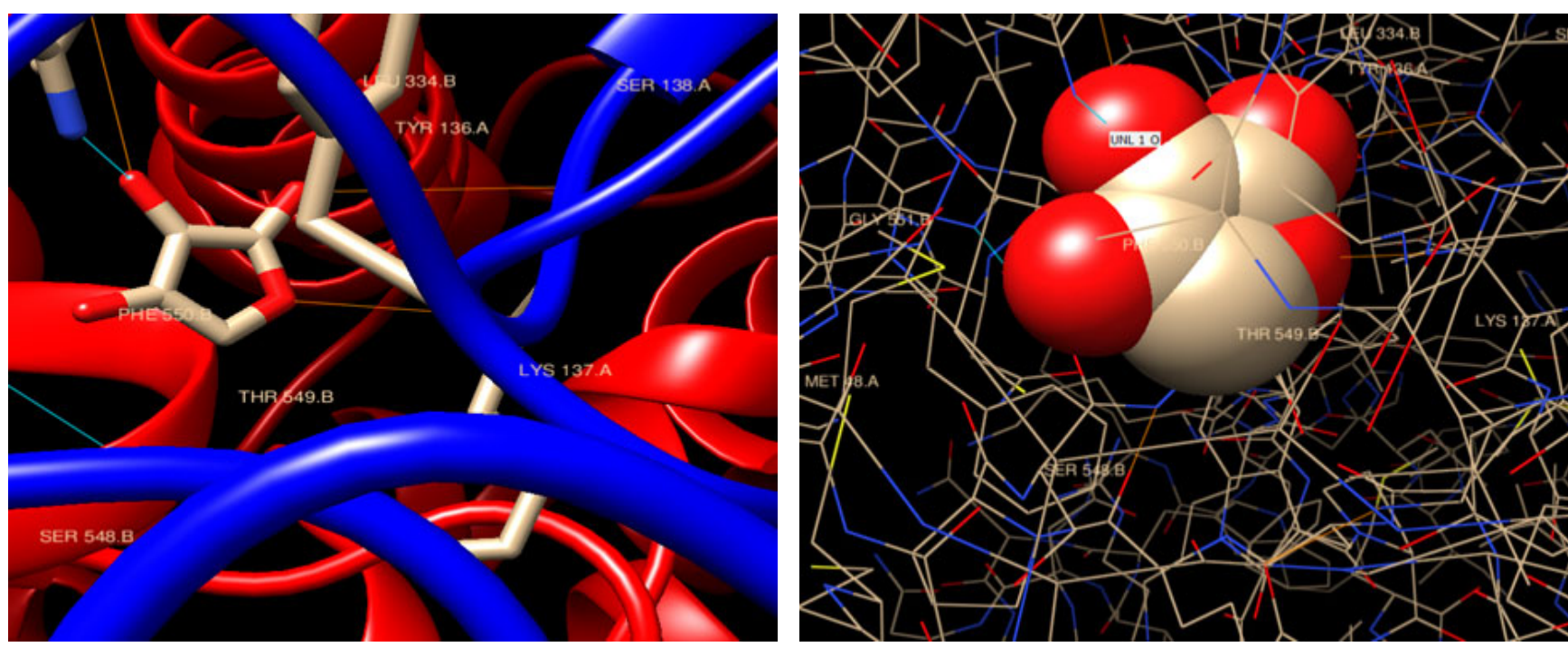


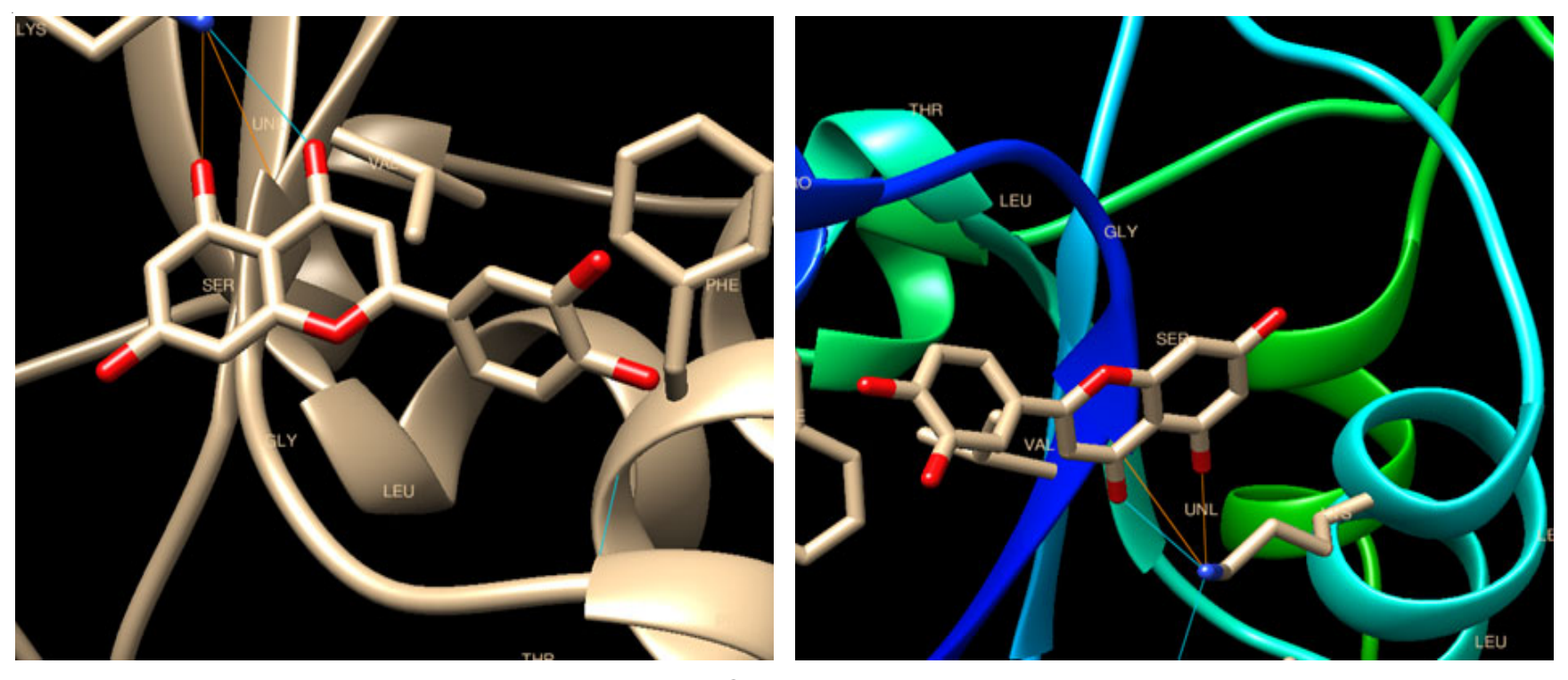

BRCA1-Luteolin
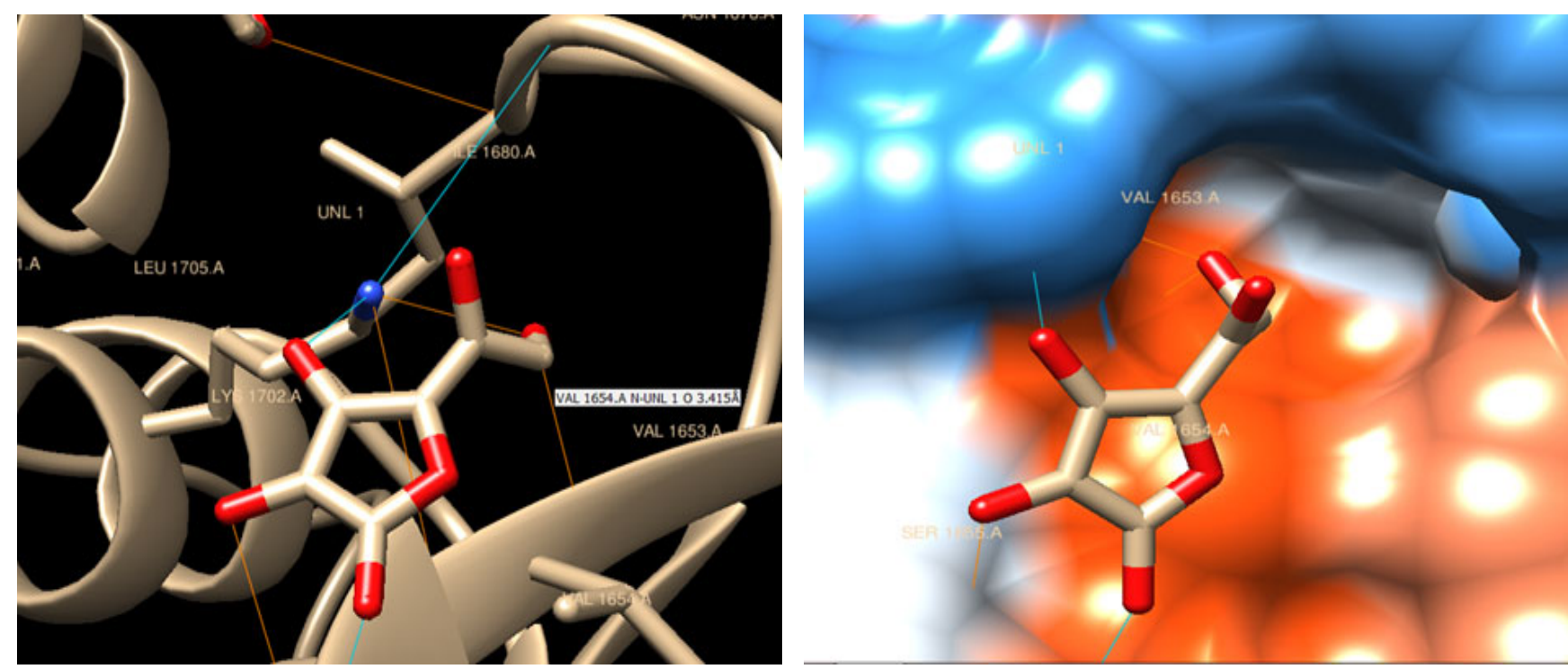

BRCA1-Ascorbic acid
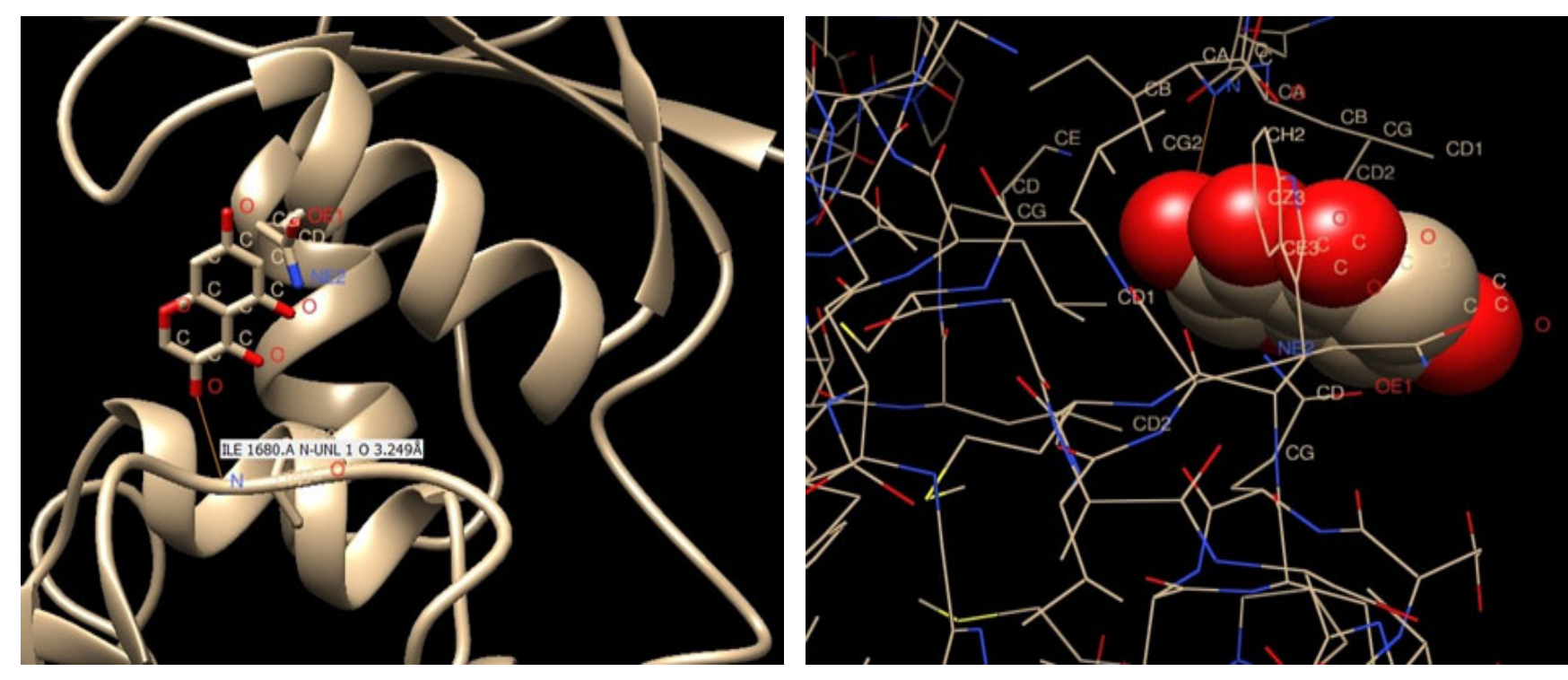

BRCA1-Quercetin

Fig. 2 Interactions between drugs and enzymes 
Ligand-enzyme interactions are shown in Fig. 2. It is evident from the images the ligand binds well with enzyme at their active site with lower (more negative) binding energy. As the number of $\mathrm{H}$-interactions increases the activity of ligand increases as well. The ligand-protein interactions are visualized using chimera. The yellow and blue lines shows the hydrogen bond ineractions.

\section{Conclusion}

The molecular docking helps in drug design and provide a good understanding of the mechanism of interaction of the drug and target protein. From this study, it is concluded that luteolin and quercetin can be subjected to further analysis and proceeding preclinical trials. Through docking study, high negative binding energy was obtained on binding of the ligand with the receptor. in vivo Studies can also be performed to evaluate the efficacy of the plant for treating diseases in animals and human beings. Docking study explained that the ligands bind to the receptor with a good binding energy. The hydrogen bonds formed refers to the strength of binding between the ligand and the receptor. Compounds exhibiting higher negative binding energy contribute to the maximum activity.

\section{CONFLICT OF INTEREST}

The authors declare that there is no conflict of interests regarding the publication of this article.

\section{REFERENCES}

1. R.N. Chopra, I.C. Chopra, K.L. Handa and L.D. Kapur, Cissus quadranglularis, In: Indigenous Drugs of India, Academic Publishers: Kolkatta, pp. 669-670 (1958).

2. K.K. Bhutani, R. Kapoor and C.K. Atal, Phytochemistry, 23, 407 (1984); https://doi.org/10.1016/S0031-9422(00)80341-6.
3. G. Mishra, S. Srivastava and B.P. Nagori, Int. J. Pharm. Tech. Res., 2, 1298 (2010).

4. V. Rajpal, Standardization of Botanicals, Eastern Publishers: New Delhi, vol. 1, pp. 77-81 (2005)

5. A.K. Srivastava, P. Srivastava, B.R. Behera and A.K. Shrivastava, Int. J. Pharma Res. Dev., 3, 207 (2011).

6. M.M. Gupta and R.K. Verma, Phytochemistry, 29, 336 (1990); https://doi.org/10.1016/0031-9422(90)89067-J.

7. M. Mehta, N. Kaur and K.K. Bhutani, Phytochem. Anal., 12, 91 (2001); https://doi.org/10.1002/pca.569.

8. S.P. Sen, Curr. Sci., 35, 317 (1966).

9. S.P. Sen, Indian J. Pharm., 26, 247 (1964).

10. C. Segsunviriya and S. Choomprabutra, A Clinical Study of Cissus quadrangularis Linn. in Hemorrhoid Patients. In: Seminar of Research and Development of Medicinal Plant. Division of Medical Research, Department of Medical Sciences, Ministry of Public Health, Thailand, pp. 54-55 (1989).

11. A. Shirwaikar, S. Khan and S. Malini, J. Ethnopharmacol., 89, 245 (2003); https://doi.org/10.1016/j.jep.2003.08.004.

12. S.S. Chajjed, P.B. Hiwani, V.A. Bastikar, C.D. Upasani, P.B. Udavant, A.S. Dhake and N.P. Mahajan, Int. J. Chemtech. Res., 2, 1135 (2010).

13. K.N. Sudha, M. Shakira, P. Prasanthi, N. Sarika, C.N. Kumar and P.A. Babu, Bioinfor, 2, 325 (2008); https://doi.org/10.6026/97320630002325.

14. A.M. Manikrao, N.S. Mahajan, R.D. Jawarkar, D.T. Mahajan, V.H. Masand and T.B. Hadda, J. Comput. Methods Mol. Design, 1, 9 (2011).

15. D. Gogoi, R.L. Bezbaruah, M. Bordoloi, R. Sarmah and T.C. Bora, Bioinfor, 8, 812 (2012); https://doi.org/10.6026/97320630008812.

16. M. Amaravani, N.K. Prasad and V. Ramakrishna, J. Springer Plus, 1, 58 (2012); https://doi.org/10.1186/2193-1801-1-58.

17. K. Sorensen, Nature, 384, 19 (1996); https://doi.org/10.1038/384019a0.

18. J.A. Duncan, J.R. Reeves and T.G. Cooke, Mol. Pathol., 51, 237 (1998); https://doi.org/10.1136/mp.51.5.237.

19. K. Yoshida and Y. Miki, Cancer Sci., 95, 866 (2004); https://doi.org/10.1111/j.1349-7006.2004.tb02195.x

20. S.S. Meenambiga, K. Rajagopal, Int. J. Pharm. Pharm. Sci., 6, 483 (2014). 